Article

\title{
Exploring the Air Pollution Control Direction of Two Typical Cities, Beijing and Wuhan, from the Air Pollution under Emergency Responses during COVID-19
}

\author{
Ada Tsan Qin \\ The Second High School Attached to Beijing Normal University
}

\begin{abstract}
During the period of COVID-19, the Chinese government implemented a series of actions to prevent the spread of the virus. It is noticed that these preventive actions have generated positive effects on air pollution in Wuhan and Beijing. And, due to the differences in city functions, geographic locations, meteorological conditions, and preventive action details between the two cities, noticeable difference is observed on how they reduced air pollution. This unfortunate incident has become a social sample for studying the industrial and livelihood activities impact on air pollution, otherwise would be highly impossible. This paper starts from observing data from NASA's realtime fine particulate matter (PM2.5) and NO2, and comparing the air pollution in this special time domain with previous years. It is discovered that both PM2.5 and NO2 have been reduced in $\mathrm{Wu}-$ han, while only NO2 has significant reduction in Beijing, during the COVID-19 responses. This suggests that the human activity suppression by the COVID-19 control yields different effects on different pollutants and in different cities. Possible reasons for such effects are analysed by considering the public health control levels as well as the pollutant migration, industrial activities, and the weather conditions.
\end{abstract}

Keywords: COVID-19; air pollution; PM2.5; NOx; MERRA-2; OMNO2

\section{Introduction}

Industrial activities, transportation, and service industries in cities have had serious impact on environment and even human being themselves. One of the most significant impacts is the pollution of the atmosphere. For example, the most well-known pollutantPM2.5, fine inhalable particles, with diameters that are generally 2.5 micrometres and smaller, can cause stroke, heart disease, lung cancer, chronic respiratory diseases and other diseases that are extremely harmful to human health. The World Health Organization (World Health Organization, WHO) research report pointed out that as many as 4.2 million people die every year due to air pollution [1]. In addition, the School of Environmental Sciences of the University of North Carolina and the National Environmental Protection Agency have proposed that in some areas with serious pollution problems, 1000 people per square kilometre per year die prematurely as a result [2].

This study selected the two of the most representative air pollutants, PM2.5 and nitrogen dioxide (NO2), as the research objects. The production of the two types of pollutants come from both man-made sources and natural sources. But in this study, the evolution of such pollutants mainly come from man-made sources, because the influencing factors of their natural sources-geographical location and meteorological conditionsare relatively stable in the period of time span of interest. Man-made sources (such as NO produced by high-temperature combustion and converted into NO2) have a great correlation with human activities. 
China's rapid economic development in recent years has led to an increase in manmade air pollution, which is still an urgent problem to be solved. At the time of the epidemic, the government issued many policies restricting Beijing and Wuhan in order to control the disease, which significantly changed the patterns of people activities in the cities and corresponding specific air pollutants. Such restrictions were impossible if it was not for the purpose of epidemic control. This provided conditions for the research of the effect of human activities on air pollution. This study selected Beijing and Wuhan as the research cities. By comparing the differences in pollutants between the implementation of different restriction actions before and after the epidemic, the study aims to develop somewhat more specific treatment of air pollution in these two cities.

The reason that Beijing and Wuhan are selected as the research cities is that they represent typical conditions in terms of geographical location, climate, and restriction actions. Regarding geographical location, Beijing is at east and at the border of the sea; Wuhan is at west and inland. Regarding climate, Beijing has a temperate monsoon climate; and Wuhan has a subtropical monsoon climate. Regarding cities functions, Wuhan is a typical heavy industry city with industries such as automobiles, shipbuilding, steel, and metallurgy; while Beijing is a representative city centred on culture and political matters, with almost zero heavy industry.

\section{Research Methods and Data Sources}

\subsection{Research Method}

The purpose of this study is to reveal the impact of changes in human activities caused by epidemic control on air pollution. This study on the pollution changes is achieved by comparing the pollutant emission during the epidemic with that at same period in history when no epidemic control was implemented. The study then analyses whether and how the correlation exist between air pollution conditions and the corresponding epidemic control actions, aiming to find some cause and effect relationship.

In this study, the historical data of the same period from 2015 to 2019 was selected as the baseline data for the pollution during the epidemic. The data for the past five years is averaged over the same period, to eliminate the data fluctuations as a set of relatively reliable data benchmarks. Comparing the data over the same period will also greatly eliminate seasonal effects. However, due to the variability of meteorological conditions, on certain dates this year, there may still be some large deviations from historical average meteorological conditions, which may cause some interferences that have nothing to do with the epidemic. Therefore, in order to further isolate the impact of epidemic control from effects of pollutant migration and dissipation caused by meteorological conditions, the study will also make necessary analyses on the meteorological conditions. The influence of meteorological factors will be discussed in the form of atmospheric self-cleaning ability index.

\subsection{Data Sources}

In this study, the reliability of the data is critical. These data include real-time changes in PM2.5-related pollutants, NO2, and meteorological conditions (including cloud cover, wind, precipitation, etc.) from the beginning of 2015 to the present. One set of the most recognized data resources in this field was picked: EarthData under the National Aeronautics and Space Administration (NASA). The wild-recognition of such databases enables an additional benefit: the study in this paper is ready to be cross checked in terms of consistency by numerous other publications which also make use of these databases.. The key data used in this study is listed below:

\subsubsection{PM2.5 Related Pollutants: MERRA-2 Aer Database}

The organic pollutant particles in PM2.5 have been found to be linearly related to organic carbon (OC, Organic Carbon) through experimental studies from Turpin [3], in 
which the urban area coefficient is $1.6+/-0.2$. Sulphate (SO4), nitrate (NO3), and ammonium salt (NH4) are the main inorganic pollutant ions. The MERRA-2 database provides separate data on dust, black carbon, and sea salt with a diameter of less than 2.5 microns, all of which are part of PM2.5. This study uses the PM2.5 correlation formula in the abovementioned literature as follows:

$$
[P M 2.5]=1.375\left[S_{4}\right]+1.6[O C]+[B C]+[D U]+[S S]
$$

where

$$
\begin{aligned}
& \mathrm{SO}_{4}: \text { Sulphate } \\
& O C \text { : Organic Carbon } \\
& B C: \text { Black Carbon } \\
& D U: \text { Dust } \\
& S S: \text { Sea Salt }
\end{aligned}
$$

This correlation is relatively accurate in the in most low-to-medium pollution situations; while in high-pollution situations, this correlation normally gives underestimated results, e.g., in higher polluted season like winter. Moreover, with relatively little nitric acid data in NASA databases, it is also underestimated in the case of high NOx contamination. However, considering the purpose of this study, comparing epidemic data with historical data, and most of the time of the epidemic is not in winter, this correlation is still very useful. Moreover, even considering the deviations the analysis of PM2.5 without NOx contamination, we can at least reveal the changes in the contributions of black carbon, organic carbon, dust, and sulphate.

\subsubsection{The NO2 Column Concentration in the Troposphere: OMNO2 Database}

The NO and NO2 present in the troposphere are polluting gases, collectively referred to as nitrogen oxides (NOx). $\mathrm{NO}$ is unstable at room temperature and will oxidize to $\mathrm{NO} 2$. Therefore, the study of NO2 has representative significance. In addition, NOx will generate nitrate in the atmosphere and cloud droplets, causing secondary pollution (one of the components of PM2.5).

2.2.3. Meteorological Data, MERRA-2 COSP Database (Cloud Data), Flx Database (Precipitation), Slv Database (Wind Speed)

These databases include various data that affect the migration, diffusion, and dissipation of pollutants, wind direction and speed at different heights, cloud cover at different heights, precipitation, and other data. In view of the large variation of this type of data

\begin{tabular}{|c|c|c|c|}
\hline Data Resource & Database & Main Data & References \\
\hline \multirow{7}{*}{ PM2.5 } & & Black Carbon Surface & \\
\hline & & Concentration & \\
\hline & & Organic Carbon Surface & \\
\hline & MERRA-2 Aer & Concentration & {$[4]$} \\
\hline & & Dust Surface Concentration & \\
\hline & & Sulphate Surface Concentration & \\
\hline & & Sea Salt Surface Concentration & \\
\hline $\mathrm{SO} 2$ & MERRA-2 Aer & SO2 Surface Concentration & [4] \\
\hline $\mathrm{NO} 2$ & $\mathrm{OMNO} 2$ & NO2 vertical density & [5] \\
\hline
\end{tabular}
within a day, these data are all selected with a resolution of $1 \mathrm{~h}$ to ensure that they can be considered as approximately static during this time interval for the purpose of the data processing.

Please refer to Table 1 for the specific data sources.

Table 1. Key databases and the corresponding references. 


\begin{tabular}{|c|c|c|c|}
\hline & & & $\begin{array}{l}\text { NO2 tropospheric column } \\
\text { density }\end{array}$ \\
\hline \multirow[b]{3}{*}{ weather } & $\begin{array}{l}\text { cloud } \\
\text { coverage }\end{array}$ & $\begin{array}{l}\text { MERRA-2 } \\
\text { COSP }\end{array}$ & $\begin{array}{l}\text { Area fraction for high clouds } \\
\text { Area fraction for middle clouds } \\
\text { Area fraction for low clouds }\end{array}$ \\
\hline & precipitation & MERRA-2 flx & total surface precipitation [7] \\
\hline & wind & MERRA-2 slv & $\begin{array}{l}2 \text { meter eastward wind speed } \\
2 \text { meter northward wind speed } \\
10 \text { meter eastward wind speed } \\
10 \text { meter northward wind speed } \\
50 \text { meter eastward wind speed } \\
50 \text { meter northward wind speed }\end{array}$ \\
\hline
\end{tabular}

\subsection{Data Range}

The scope of this study was focused on Beijing and Wuhan and their surrounding areas. The range of longitude and latitude selected for Beijing (within the rectangular range of $\left(115.625^{\circ}\right.$ east longitude, $39.5^{\circ}$ north latitude) and $\left(116.875^{\circ}\right.$ east longitude, $40.5^{\circ}$ north latitude)) is consistent with the numerical data resolution given by NASA -0.625 degrees longitude and 0.5 degrees latitude. The entire area includes a data array composed of 9 points in three horizontal and three vertical data. The distribution of specific areas and data points is shown in Figure 1.

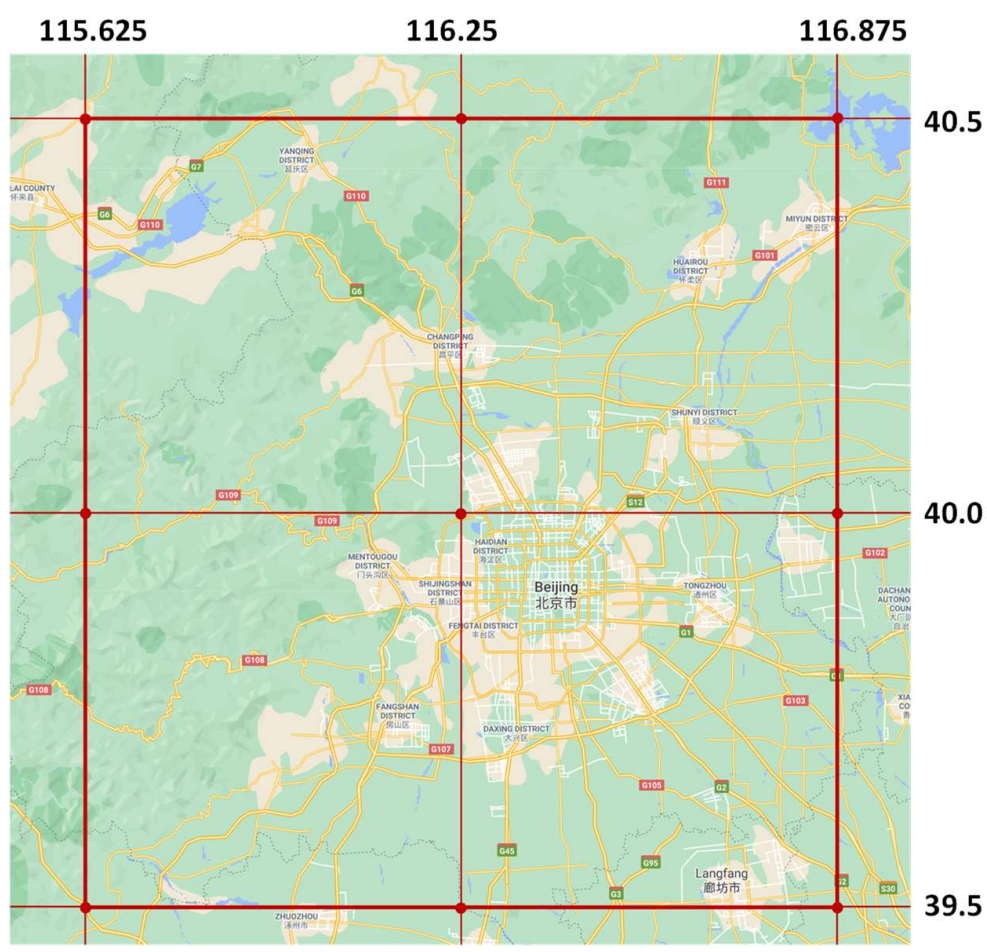

Figure 1. Regional scope and data point distribution of Beijing.

Similarly, the data range of Wuhan is selected in the rectangular range formed by $\left(113.75^{\circ} \mathrm{E}, 30.0^{\circ} \mathrm{N}\right)$ and $\left(115^{\circ} \mathrm{E}, 31.0^{\circ} \mathrm{N}\right)$, and contains an array of three horizontal, three vertical and nine data points as shown in Figure 2. 


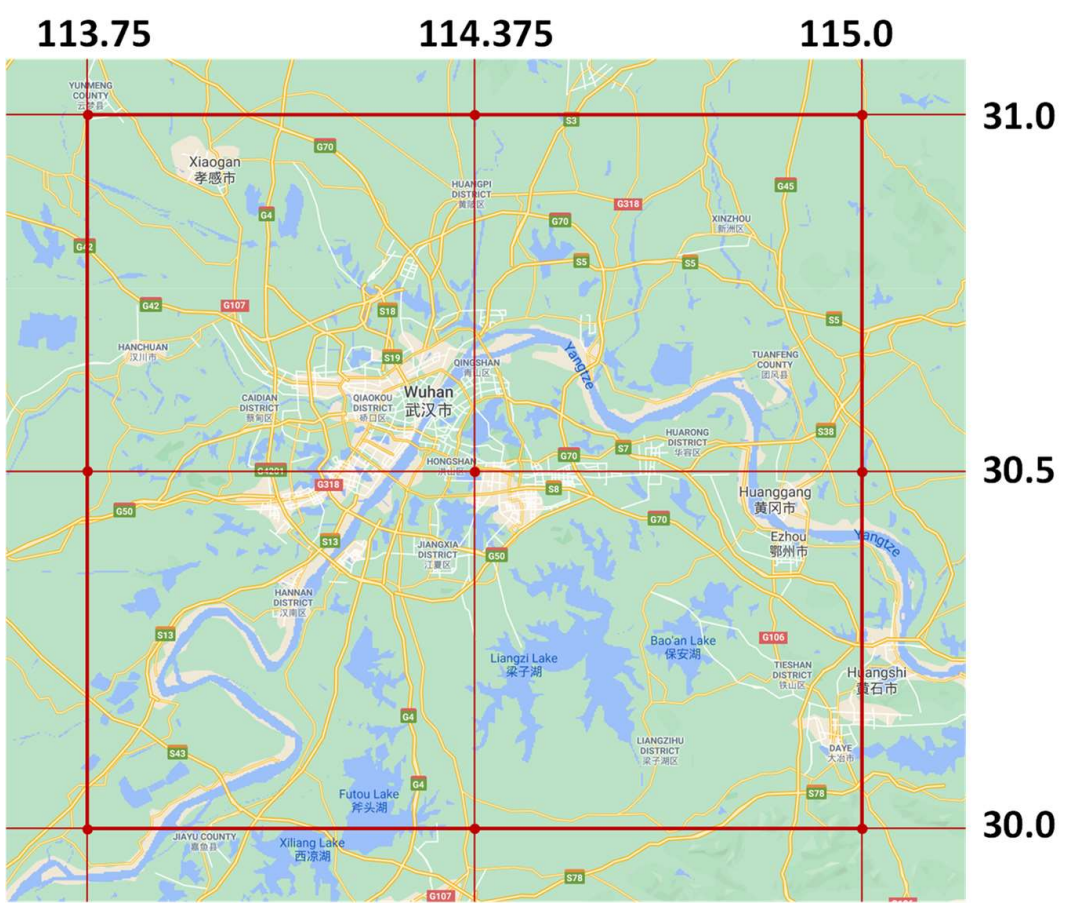

Figure 2. Regional scope and data point distribution of Wuhan.

In order to analyze the impact of the epidemic on the pollution situation, this study compared the pollution in 2020 in different periods and the pollution over the same periods of time in the past five years. Therefore, the selection of the above data starts at 00:00 on 1 January 2015, and ends at 23:00 on 31 July 2020. Since the migration process of pollutants is affected by many complex factors which vary within a day with high randomness, this study tries to select a database with a high time resolution: except for $\mathrm{NO} 2$, the rest are all 1-h interval data.

In order to analyse the changes more clearly in pollutants after and before the epidemic, this study selected PM2.5 and $\mathrm{NO}_{2}$ data from 2015 to 2019. And considering the deviation caused by the influence of some individual factors, this study takes the average value of the previous five years, and performs a five-day average calculation to smoothen the curve for comparison with 2020.

$\mathrm{NO}_{2}$ data is affected by more complex factors highly affected by the sky cloudiness. Therefore, in some weather conditions, NASA did not provide data, but the collected data is sufficient to prove the overall trend of $\mathrm{NO}_{2}$.

\subsection{COVID-19 Control Actions in Beijing and Wuhan}

In order to study the impact of COVID-19 control actions on pollution, this study collected the control actions taken by Beijing and Wuhan as in Tables 2 and 3. 
Table 2. Control Actions taken in Beijing COVID-19 period.

\begin{tabular}{|c|c|c|}
\hline Date & Control Action Taken & Reference \\
\hline $\begin{array}{l}24 \text { January } \\
2020\end{array}$ & $\begin{array}{l}\text { Beijing launched level one response to } \\
\text { major public health emergencies. }\end{array}$ & $\begin{array}{l}\text { Beijing Municipal People's Government } \\
\text { http://www.beijing.gov.cn/ywdt/gzdt/202001/t20200124_1828 } \\
\text { 366.html }\end{array}$ \\
\hline 30 April 2020 & $\begin{array}{l}\text { The emergency response level of public } \\
\text { health emergencies in Beijing was } \\
\text { lowered from level one to two }\end{array}$ & $\begin{array}{l}\text { Beijing Municipal People's Government } \\
\text { http://www.beijing.gov.cn/gongkai/hygq/202004/t20200429_1 } \\
\text { 888374.html }\end{array}$ \\
\hline 6 June 2020 & $\begin{array}{l}\text { The emergency response level of public } \\
\text { health emergencies in Beijing was } \\
\text { lowered from level two to level three }\end{array}$ & $\begin{array}{l}\text { People's Government of Dongcheng District, Beijing } \\
\text { http://www.bjdch.gov.cn/n3952/n9279505/c9657416/content.h } \\
\text { tml }\end{array}$ \\
\hline 16 June 2020 & $\begin{array}{l}\text { Beijing's emergency response level was } \\
\text { raised from three to two. }\end{array}$ & $\begin{array}{l}\text { People's Government of Changping District, Beijing } \\
\text { http://www.bjchp.gov.cn/cpqzf/315734/bmdt/5276930/index.h } \\
\text { tml }\end{array}$ \\
\hline 20 July 2020 & $\begin{array}{l}\text { Beijing emergency response level adjusted } \\
\text { to level three }\end{array}$ & $\begin{array}{l}\text { Beijing Human Resources and Social Security Bureau } \\
\text { http://rsj.beijing.gov.cn/bm/ztzl/yqzl/bj/202007/t20200720_195 } \\
\text { 1985.html }\end{array}$ \\
\hline
\end{tabular}

Table 3. Control Actions taken in Wuhan COVID-19 period.

\begin{tabular}{|c|c|c|}
\hline Date & Control Action Taken & Reference \\
\hline $\begin{array}{l}24 \text { January } \\
2020\end{array}$ & $\begin{array}{l}\text { Launched level one response to major } \\
\text { public health emergencies. }\end{array}$ & $\begin{array}{l}\text { Novel Coronavirus Infected Pneumonitis Epidemic } \\
\text { Prevention and Control Headquarters, Wuhan (No. 1) }\end{array}$ \\
\hline 2 May 2020 & $\begin{array}{l}\text { The emergency response level of public } \\
\text { health emergencies in Wuhan was } \\
\text { lowered from level one to two }\end{array}$ & $\begin{array}{l}\text { Sina News } \\
\text { http://news.sina.com.cn/o/2020-05-01/doc- } \\
\text { iircuyvi0890448.shtml }\end{array}$ \\
\hline 13 June 2020 & $\begin{array}{l}\text { The emergency response level of public } \\
\text { health emergencies in Wuhan was } \\
\text { lowered from level two to level three }\end{array}$ & $\begin{array}{l}\text { Novel Coronavirus Infected Pneumonitis Epidemic } \\
\text { Prevention and Control Headquarters, Wuhan (No. 23) }\end{array}$ \\
\hline 10 August & Junior Middle school grade 1 and Grade & 2 Novel Coronavirus Infected Pneumonitis Epidemic \\
\hline 2020 & return to school & Prevention and Control Headquarters, Wuhan (No. 24) \\
\hline
\end{tabular}

Such control actions responding to public health emergencies are mainly to reduce the flow of people and restrict the highly concentrated population places, such as restricts of inter-provincial and municipal tourism, entry and exit control of residential areas, 14day quarantine of high-risk groups, closure of theatres and supermarkets or flow restriction. These restrictions had great impact on transportations and some tertiary industries. The severity of the epidemic represented by the response level from high to low is first-level response, second-level response, and third-level response. But the control action taken at the same response level had very different impact on different cities. Put secondary industry as specific examples in Beijing and Wuhan: many large manufactures of enterprises/companies are located Wuhan; Whereas in Beijing, the secondary industry is relatively a small portion and there are few manufactures but mainly offices. Under response level 1, majority of the enterprises in Wuhan need to suspend production and stop all activities[9-11], while there is no major impact on the entire industry[12-14] in Beijing as the employees can still work but from home due to their characteristic of the work.

\section{Comparison of Changes in Pollutants during the Epidemic}

This chapter is to compare the pollution data during the epidemic period and the past five years in the same period and explore the relationship between the rise and fall of various pollutants with time, in Beijing and Wuhan. The pollutants studied include PM2.5 and $\mathrm{NO}_{2}$. 
In order to mitigate the impact of extreme data and highlight the overall trend of change, all data in this chapter are processed using a five-day moving average method.

The data in this chapter used the nine-points-sampled data described session 2.3, and the corresponding average value (except explicitly named otherwise).

\subsection{Beijing}

In this study, the extracted black carbon (BC), organic carbon (OC), dust (DU), sulphate (SO4) and sea salt (SS) data were used to calculate PM2.5 through Equation (1). Figure 3 shows a comparison of the PM2.5 surface concentration in 2020 and the average of the same period in the past five years. The figure shows the time points of major changes in epidemic control measures:

A. When the epidemic began, Beijing initiated a first-level response

B. Response level changes from one to two

C. Response level changes from two to three

D. Response level raises level three to level two

E. Response changes from level two to level three

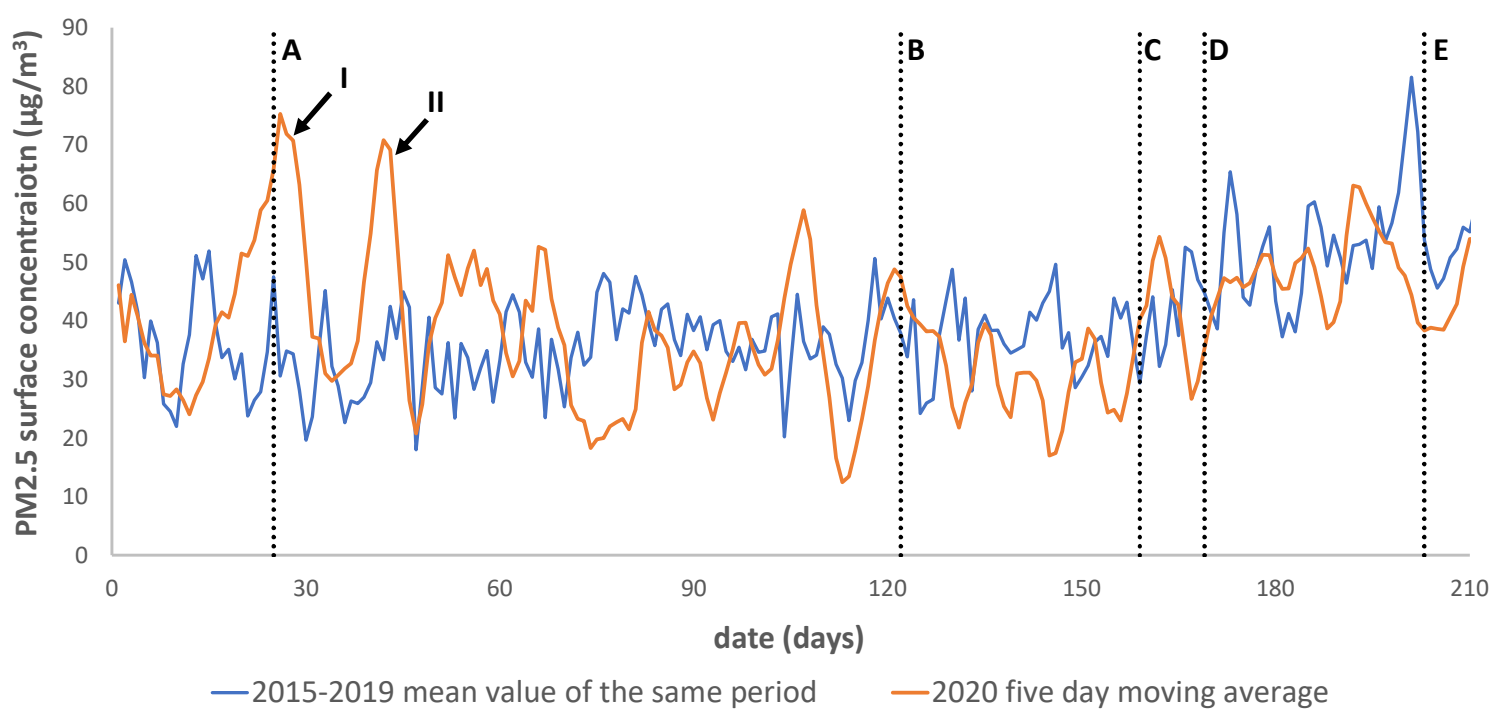

Figure 3. Comparison of the change of PM2.5 concentration in Beijing in 2020 with the average value of the same period in the past five years.

From Figure 3, it is found that in 2020, in the first two months of the beginning of the year, PM2.5 has a large increase compared with the average of the same period in previous years. Especially during the end of January and early February, there were two periods of heavy pollution significantly higher than in previous years (shown as two peaks I and II in the figure). The relative abnormal behaviour of these two peaks will be discussed in detail later. In early March and mid to late May, PM2.5 decreased slightly. For the rest of the time, the trend was basically in line with the average of the previous five years.

Table 4 listed the different stages in the epidemic period according to different control actions, the corresponding PM2.5 average level in these stages, and the ones during the same period of history. It can be seen from the table that during the entire epidemic period, the pollution increased significantly in some periods and decreased significantly in some other periods; the magnitude of the increase and decrease has no obvious correlation with the level of epidemic control. The total average pollution level is roughly the same as the historical average for the overall seven months epidemic period in this study. 
Table 4. Comparison of PM2.5 in different periods of the epidemic with the historical 2015-2019 average of the same period, Beijing.

\begin{tabular}{|c|c|c|c|c|c|}
\hline \multirow[b]{2}{*}{ Date Period } & \multirow[b]{2}{*}{ Response Level } & \multirow[b]{2}{*}{$\begin{array}{c}\text { Year 15-19 } \\
\text { Average }\end{array}$} & & \multicolumn{2}{|c|}{ Unit $\left(\mu \mathrm{g} / \mathrm{m}^{3}\right)$} \\
\hline & & & 2020 & 2020 Increase & $\begin{array}{c}\text { Year } 15-19 \\
\text { Standard } \\
\text { Deviation }\end{array}$ \\
\hline $1 / 1-23 / 1$ & $\begin{array}{c}\text { Before any responses } \\
\text { implemented }\end{array}$ & 36.17 & 38.39 & $6.13 \%$ & 6.60 \\
\hline $24 / 1-29 / 4$ & Level 1 & 35.24 & 38.53 & $9.34 \%$ & 2.15 \\
\hline $30 / 4-5 / 6$ & Level 2 & 37.52 & 31.10 & $-17.10 \%$ & 1.73 \\
\hline $6 / 6-16 / 6$ & Level 3 & 40.81 & 41.69 & $2.17 \%$ & 4.98 \\
\hline $17 / 6-19 / 7$ & Level 2 & 52.20 & 48.70 & $-6.69 \%$ & 4.05 \\
\hline $20 / 7-31 / 7$ & Level 3 & 54.95 & 45.84 & $-16.58 \%$ & 3.71 \\
\hline $1 / 1-31 / 7$ & Response Average & 39.76 & 39.38 & $-0.97 \%$ & 1.78 \\
\hline
\end{tabular}

Moreover, the following components were extracted from the NASA database: sulphate $\left(\mathrm{SO}_{4}\right)$, organic carbon (OC), black carbon (BC), and dust (DU). Figure 4 shows, in turn, the changes of these components during the epidemic and the corresponding historical five-year averages for the same period:

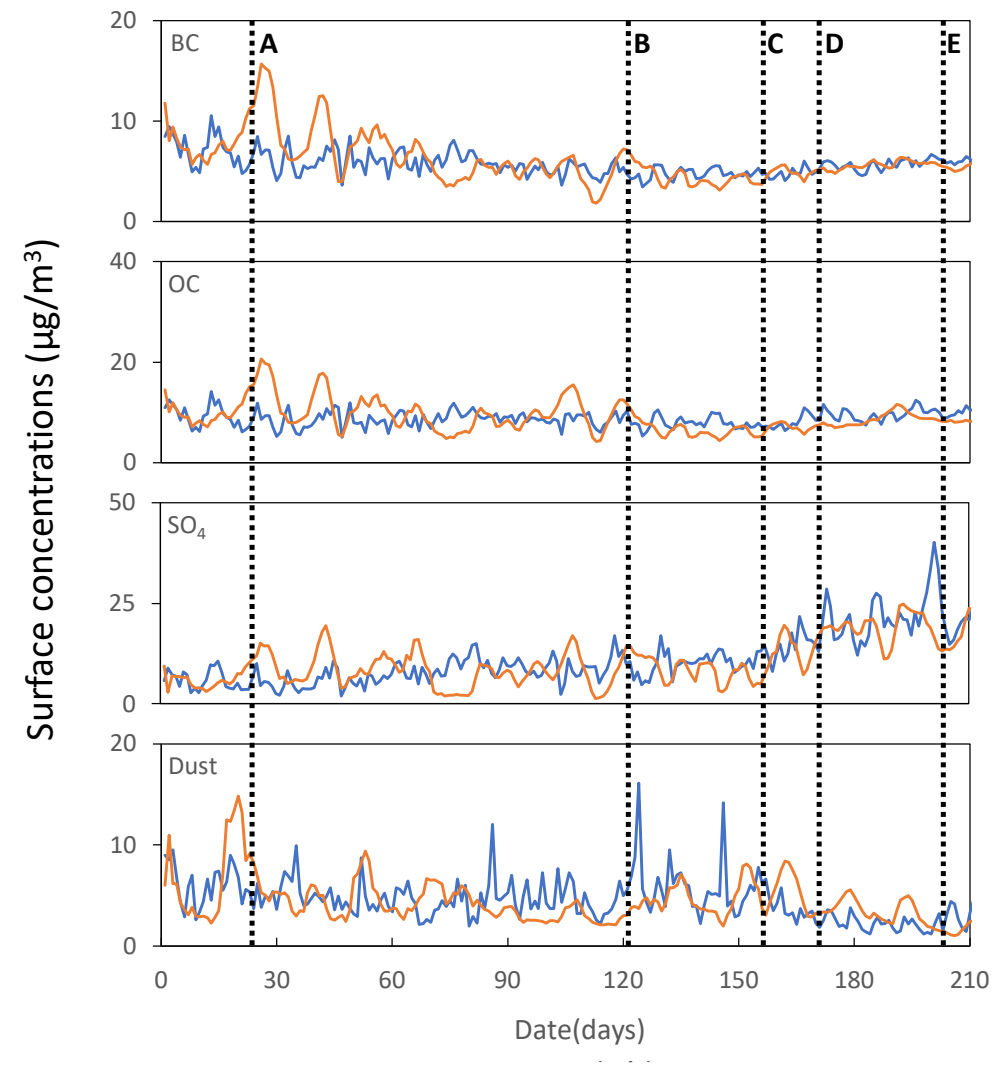

Figure 4. Comparison in between the average value of pollutants during the epidemic period in Beijing and that of the historical corresponding period.

From Figure 4, it can be concluded that almost all the sub-items have the same trend as the average value of the past five years, and there is no significant change. Therefore, in combination with the previous paragraph, it can be concluded that the control action 
implemented during the epidemic did not have a significant impact on Beijing's PM2.5 content.

Similar analysis was done on $\mathrm{NO}_{2}$. (Figure 5). It can be seen that the behaviour of the concentration of pollutant $\mathrm{NO}_{2}$ is significantly different from PM2.5. In the seven months of 2020, the $\mathrm{NO}_{2}$ tropospheric column concentration is significantly lower than the average over the same period, from 2015 to 2019. The average value of the overall tropospheric column concentration in 2020 is calculated as $1.06 \times 10^{-16} \mathrm{~kg} / \mathrm{m}^{2}$, and the corresponding historical average for the same period is $1.4 \times 10^{-16} \mathrm{Kg} / \mathrm{m}^{2}$, which is a drop of nearly $30 \%$ compared to the data during the epidemic period.

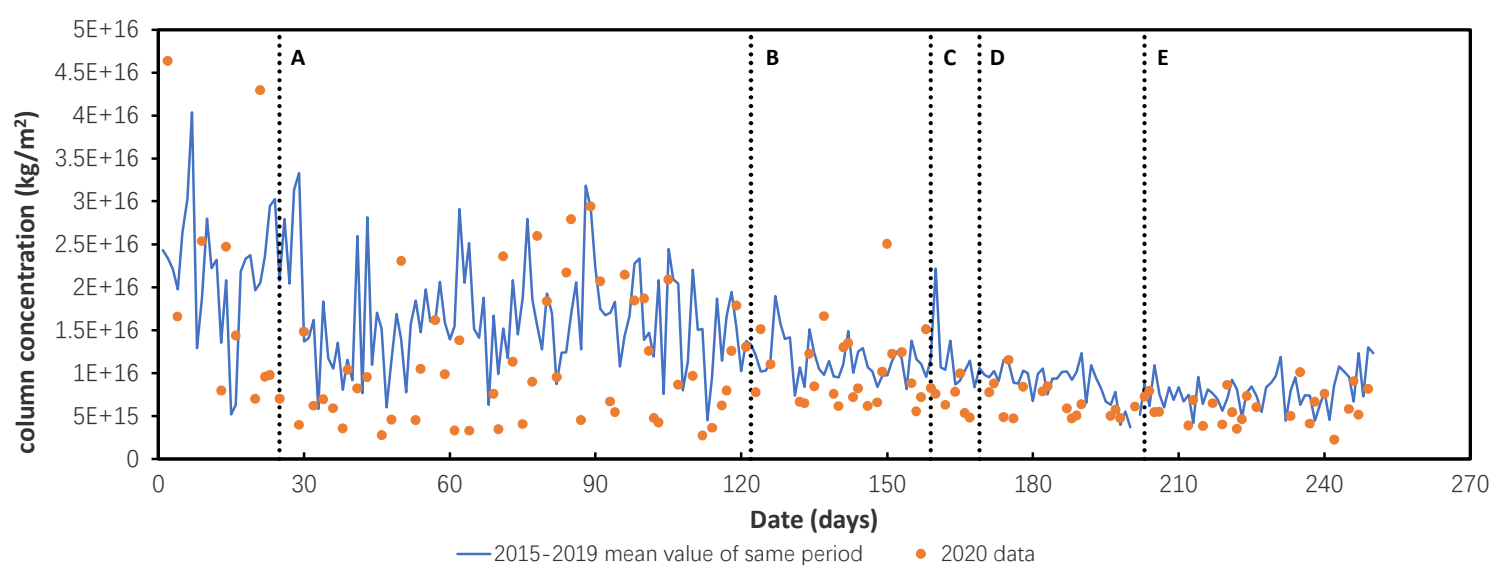

Figure 5. Comparison of $\mathrm{NO} 2$ during the epidemic with the historical mean value over the same period. (Because $\mathrm{NO}_{2}$ is greatly affected by cloud coverage, the database does not provide continuous changes in NO2 over time throughout the year, but the existing valid data can still show obvious trends.)

To summarize, during the epidemic period, Beijing's PM2.5 did not change significantly compared with previous years. But there is a significant decrease in $\mathrm{NO}_{2}$.

\subsection{Wuhan}

The same analysis was applied to Wuhan, and the following conclusions were obtained.

The comparison between Wuhan PM 2.5 during the epidemic period and the same period in history is shown in Figure 6, where the important time points of the epidemic control measures are marked:

A. At the beginning of the epidemic, Wuhan City initiated the Level 1 response

B. Response level changes from one to two

C. Response changes from level two to level three

Figure 6 shows that for most of the time in February, Wuhan's PM2.5 emissions in 2020 had a significant decrease compared with the same period in prehistoric times. In May and June, although the amount of decrease was reduced, it was still a decrease. A slight rebound in July was also observed. 


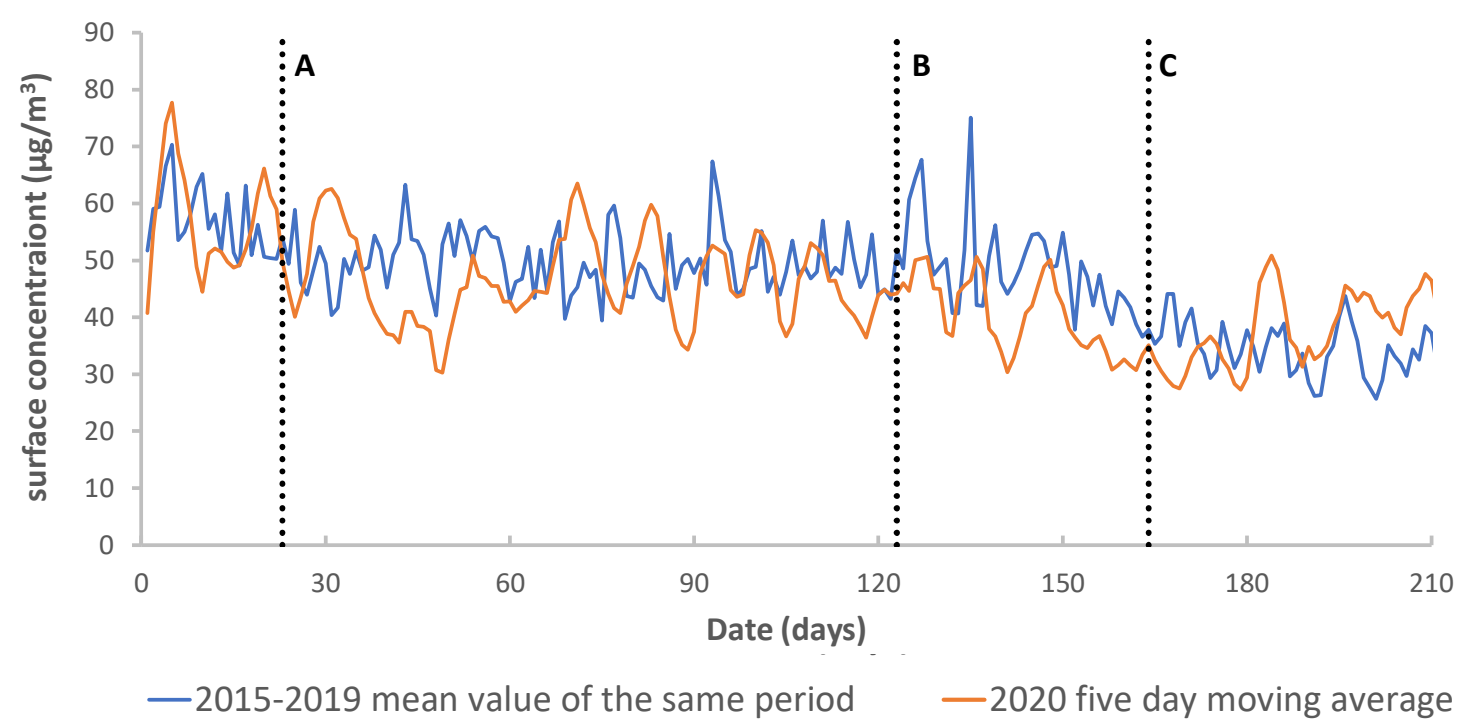

Figure 6. Comparison of PM2.5 in Wuhan during the epidemic with the historical average of the same period.

Similar as the analysis on Beijing, we compared the PM 2.5 level during different period of response level for Wuhan (Table 5). During the level 1 response and the level 2 response periods, a significant PM 2.5 decrease was observed in 2020 compared with the previous five years; while at level 3 response period, an increase was observed. Overall, the emergency response action taken during the epidemic period results in a noticeable improvement for Wuhan's PM2.5 pollution.

Table 5. Comparison of PM2.5 pollution under different epidemic control actions with the historical average over the same period, Wuhan.

\begin{tabular}{|c|c|c|c|c|c|}
\hline \multirow[b]{2}{*}{ Date Period } & \multirow[b]{2}{*}{ Response Level } & \multirow[b]{2}{*}{$\begin{array}{c}\text { Year 15-19 } \\
\text { Average }\end{array}$} & \multirow[b]{2}{*}{2020} & \multicolumn{2}{|c|}{ unit: $\mu \mathrm{g} / \mathrm{m}^{3}$} \\
\hline & & & & 2020 Increase & $\begin{array}{c}\text { Year 15-19 } \\
\text { Standard Deviation }\end{array}$ \\
\hline $1 / 1-23 / 1$ & $\begin{array}{c}\text { Before any responses } \\
\text { implemented }\end{array}$ & 56.74 & 57.47 & $1.29 \%$ & 5.10 \\
\hline $23 / 1-1 / 5$ & Level 1 & 49.53 & 46.48 & $-6.17 \%$ & 2.00 \\
\hline $2 / 5-12 / 6$ & Level 2 & 48.59 & 39.79 & $-18.10 \%$ & 4.63 \\
\hline $12 / 6 / 12-31 / 7$ & Level 3 & 34.10 & 38.01 & $11.47 \%$ & 2.91 \\
\hline $1 / 1-31 / 7$ & Response Average & 46.57 & 44.40 & $-4.67 \%$ & 2.55 \\
\hline
\end{tabular}

Similarly, we compared the changes in the mean value of $\mathrm{NO}_{2}$ during the epidemic and the same period in history. These changes are shown in Figure 7: 


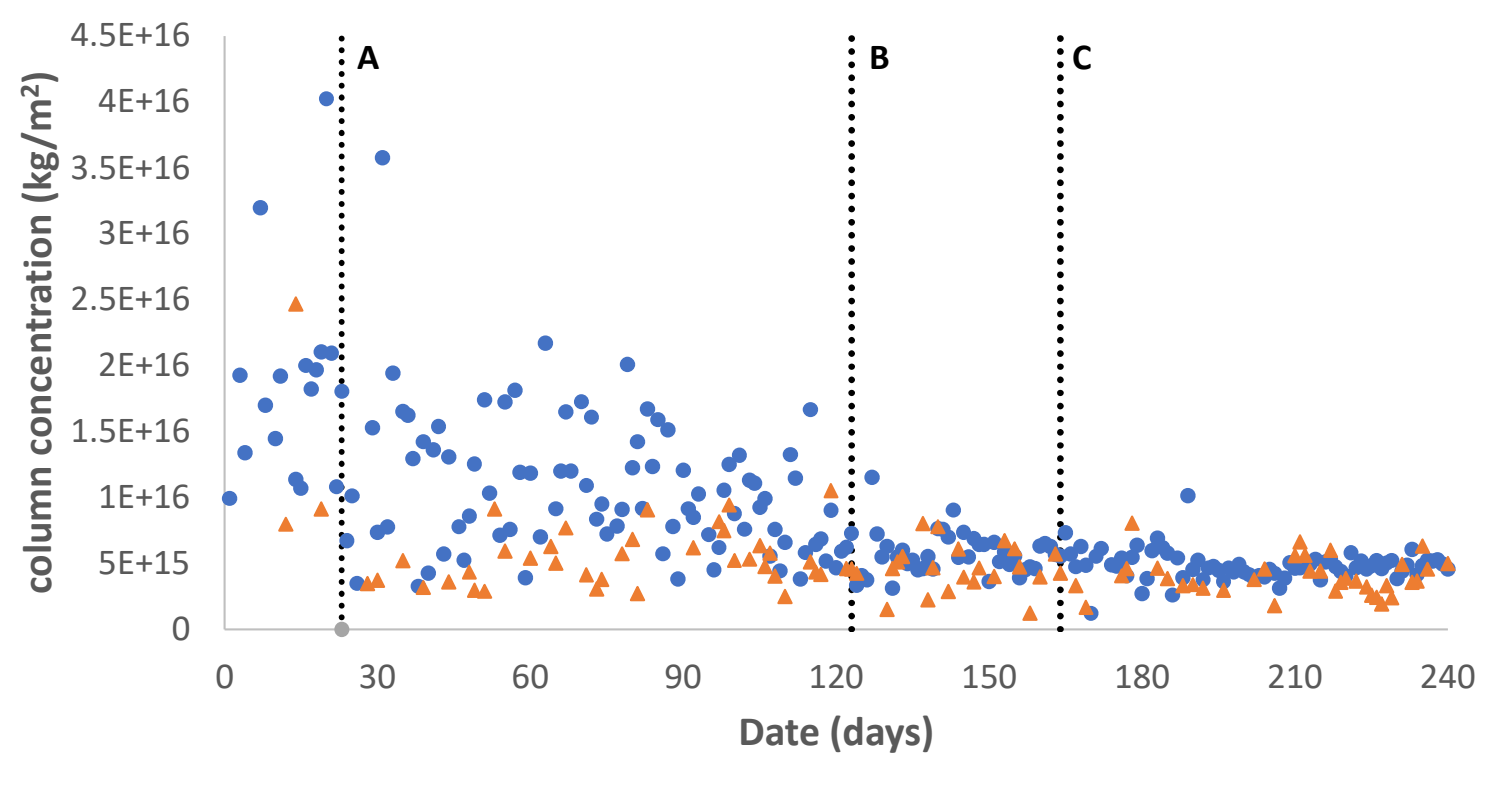

- 2015-2019 mean value of seame period $\quad \Delta 2020$ values

Figure 7. Comparison of $\mathrm{NO}_{2}$ during the Wuhan epidemic with the historical average over the same period. (Because $\mathrm{NO}_{2}$ is greatly affected by cloud cover, the database does not provide continuous changes in $\mathrm{NO} 2$ over time throughout the year, but the existing valid data can still show obvious trends.)

Figure 7 shows that the nitrogen oxide tropospheric column density in 2020 has a significant decrease than the average value of the previous five years. And the period of greatest decline was before May. Through the time comparison in the table, it is noticed that this is the part with the strictest epidemic control (Level 1 and 2). After the relaxation of epidemic control, the 2020 decrease vs. the last five years has gradually narrowed. Nitrogen oxides are mainly the products of combustion. Almost all types of combustion produce more or less nitrogen oxides, including the emission from the car and industrial scale high temperature combustion processes. Therefore, it is more reasonable to use nitrogen oxides to represent the combustion situation in cities. This shows that the epidemic has a far-reaching impact on Wuhan as a lot of secondary industrial manufactures are in the city. The data can also reflect this change intuitively: during the first seven months, the average value of the overall tropospheric column concentration (column concentration) in 2020 is $5.11 \times 10^{-15} \mathrm{~kg} / \mathrm{m}^{2}$, while the corresponding historical average over the same period is $8.33 \times 10^{-15} \mathrm{~kg} / \mathrm{m}^{2}$. In contrast, $\mathrm{NO}_{2}$ dropped by nearly $40 \%$ during the epidemic.

In conclusion, various types of pollutant in Wuhan have significant decline compared to the same period in history. Among them, the change in PM2.5 is small, and the decline in NO2 is significant.

\section{Discussion and Analysis}

To sum up the analysis for Beijing and Wuhan cities during epidemic period:

- There was no obvious change in Beijing's PM2.5 pollution, and the nitrogen oxide index dropped significantly.

- Wuhan's PM2.5 pollution has a slight yet notable decrease, and the nitrogen oxide index has dropped significantly.

In both cities, NOx is affected much more significantly than PM2.5 by the epidemic control actions; while PM2.5 is more affected in Wuhan than Beijing. Such different effects then need to explain. By comparing the government's control actions over these two cities mentioned in the previous sessions, there is not much difference in the control intensity 
nor the timeline. So, this chapter is to explore other factors that lead to different pollutant results in these two regions. The questions to be answered are:

1. Why does PM2.5 in different cities behave differently under similar control actions?

2. Why does PM2.5 and NOx react differently under same control actions in the same cities?

In the first session, it was mentioned that there are factors affecting local pollution like traffic and industry happened locally. In addition to local pollution emissions, the other two factors are also very important: the migration of surrounding pollutants, and the meteorological conditions affecting the dissipation of pollutants. Literature [15] pointed out that for Beijing, the migration of pollutants is mainly affected by wind speed and wind direction. Therefore, the migration of horizontal pollutants was studied. The migration of vertical pollutants can be regarded as the dissipation process of pollutants, which does not affect the research results. In this study it is hypothesized that the horizontal migration of surface pollutants is mainly driven by convection, while diffusion is relatively weak. Additionally, this paper assumes that the resolution of the hourly weather data is fine enough for the data to be considered as approximately static during this time interval.

According to the previous sessions, the scope of our research on pollution in Beijing is included in the rectangle area formed by $\left(115.625^{\circ} \mathrm{E}, 39.5^{\circ} \mathrm{N}\right)$ and $\left(116.875^{\circ} \mathrm{E}, 40.5^{\circ} \mathrm{N}\right)$. The rectangle area is divided by three horizontal and three vertical lines, in total nine data points (Figure 1). We use the 8 boundary points outlay the region of interest. The eastwest distance is set as $\mathrm{x}$ direction and north-south distance as $\mathrm{y}$ direction. The interested study scope is set as the atmosphere above the area as a rectangular parallelepiped extending from the ground to a height $h$. the pollutants entering and leaving the cuboid is considered. The sum of the pollutant fluxes on the four sides of the rectangle is therefore the net import rate of air pollutants from neighbourhood to Beijing.

According to the data by the NASA database (Table 1), the direction of the wind is classified into two categories: east-west direction (indicated by $\mathrm{U}$ ) and north-south direction (indicated by V), with east and north as positive directions respectively. Therefore,

Pollutant Net Import Rate $=$ $=$ The net pollutants migrated in from East/West boundaries

+ the net pollutants migrated in from North/South boundaries

As shown in Figure 8

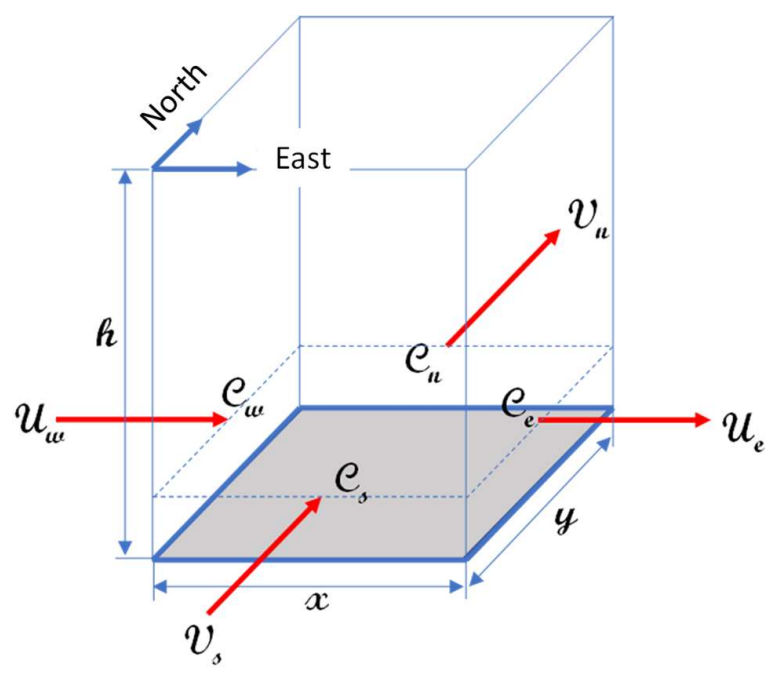

Figure 8. Atmospheric Pollutant Migration Model. 
Substituting the dimension and wind velocity variables:

$$
T_{b}=\frac{U_{w} C_{w} y h-U_{e} C_{e} y h+V_{s} C_{s} x h-V_{n} C_{n} x h}{x y h}=\frac{U_{w} C_{w}-U_{e} C_{e}}{x}+\frac{V_{s} C_{s}-V_{n} C_{n}}{y}
$$

where:

$T_{b}$ : pollutants net input rate to Beijing, $\mathrm{kg} / \mathrm{m}^{3} \mathrm{~s}$

$U_{w}, U_{e}$ : Eastward wind speed on the west and east boundaries, $\mathrm{m} / \mathrm{s}$

$V_{s}, V_{n}$ : Northward wind speed on the south and north boundaries, $\mathrm{m} / \mathrm{s}$

$C_{w}, C_{e}, C_{s}, C_{n}$ : Pollutants Concentration on the four boundaries, $\mathrm{kg} / \mathrm{m}^{3}$

$x, y$ : east-west distance, north-south distance, $m$

Using this formula, the net input of external pollutants into Beijing is calculated. Since there are three data points on each boundary, a three-point weighted average method is adopted to represent its average, for example, at the western boundary:

$$
\overline{U_{w}}=\frac{\left(U_{w, 1}+2 U_{w, 2}+U_{w}\right)}{4}
$$

The rest can be deduced similarly.

Figure 9 shows the changes over time of Beijing's PM2.5 (net input rate) in 2020. In order to better represent the trend, the data in the figure uses a 24-h moving average smoothing process. From the figure, it is seen that the net input of PM2.5 in Beijing is positive for most of the year. This shows that Beijing is a net importer of PM2.5. At the same time, it is seen that the local PM2.5 pollution level in Beijing has a strong positive correlation with the input rate, especially in the first six months.
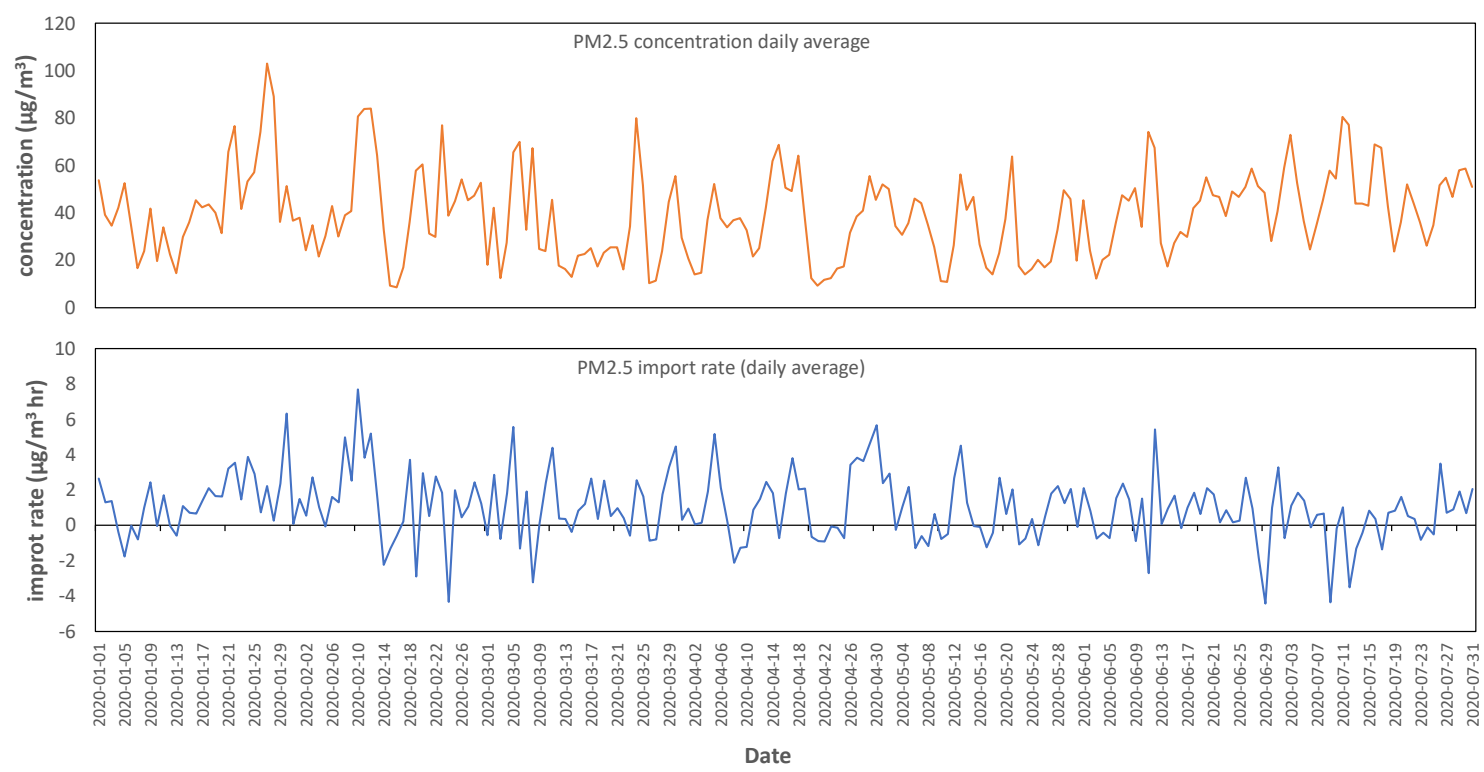

Figure 9. Beijing's PM2.5 net input rate and PM2.5 concentration changes from January to July 2020.

The epidemic control actions taken during the epidemic in the surrounding areas of Beijing including Hebei Province and Tianjin city were roughly like those of Beijing in terms of intensity and time. The decline in human activities in the surrounding areas should have a roughly similar trend to that of Beijing. Hence, the tertiary industry and traffic pollution in the neighborhood of Beijing caused by the epidemic was roughly like the local trends in Beijing. However, what makes differences is the impact of the epidemic control action on heavy industries, since Beijing has few local heavy industries. The major neighbor, Hebei Province, however, is one of the major bases of China's heavy indus- 
tries, especially for the steel industry, which accounts for nearly half of the province's industrial pollutant emissions [16]. So, steel production in Hebei Province could represent the increase or decrease of industrial pollution in the surrounding areas during the epidemic period. Table 6 lists the year-on-year growth rates of major steel products in Hebei Province during the epidemic period [17]. It is noticed that during the epidemic, the productivity of major steel products did not decline. On the contrary, there was a slight increase. This shows that the major industrial pollution sources around Beijing during the epidemic were less affected by the epidemic.

Table 6. the year-on-year growth rate of steel production in Hebei Province from January to July 2020.

\begin{tabular}{ccccccc}
\hline $\begin{array}{c}\text { Year-on-Year } \\
\text { Output Increase (\%) }\end{array}$ & $\begin{array}{c}\text { Januay- } \\
\text { February }\end{array}$ & March & April & May & June & July \\
\hline Pig iron & 5.3 & 4.8 & 2.2 & 2.4 & 3.1 & 6 \\
\hline Crude steel & 3.7 & 0.2 & -2 & -1.8 & -1.2 & 2 \\
\hline Steel & 0.1 & 1.9 & 1.8 & 2.7 & 4.3 & 6 \\
\hline
\end{tabular}

Therefore, a reasonable explanation for the fact that Beijing's PM2.5 pollution situation did not decline during the epidemic is that the source of PM2.5 in Beijing mainly comes from the input of surrounding industrial pollution. And the impact of the epidemic control actions on the surrounding major industrial pollution sources is far lower than its impact on human activities. Hence Beijing has not experienced a significant reduction in PM2.5 pollution.

At the same time, using the data on wind speed, cloud coverage, precipitation, and other data in the from NASA database (Table 1), a corresponding analysis of the impact of meteorological conditions on the spread of pollution in Beijing is made. Literature [18] puts forward a national standard in which the concept of atmospheric self-purification ability index is defined. This index classifies the atmospheric self-purification ability into 6 grades corresponding to weather conditions' ability to dissipate and remove pollutants. The specific classification criteria are shown in Table 7.

Table 7. Classification of air pollutant self-purification capacity.

\begin{tabular}{lll}
\hline Grade & $\begin{array}{l}\text { Atmospheric Self-Purification } \\
\text { Capacity Index }\end{array}$ & Description \\
\hline Grade One & $\mathrm{A}>30.0$ & $\begin{array}{l}\text { Very beneficial to the removal of } \\
\text { atmospheric pollutants }\end{array}$ \\
\hline Grade Two & $30.0 \geq \mathrm{A}>12.0$ & $\begin{array}{l}\text { beneficial to the removal of atmospheric } \\
\text { pollutants }\end{array}$ \\
\hline Grade Three & $12.0 \geq \mathrm{A}>7.0$ & $\begin{array}{l}\text { The removal effect on atmospheric } \\
\text { pollutants is not obvious }\end{array}$ \\
\hline Grade Four & $7.0 \geq \mathrm{A}>5.0$ & $\begin{array}{l}\text { It is not very conducive to the removal } \\
\text { of atmospheric pollutants }\end{array}$ \\
\hline Grade Five & $5.0 \geq \mathrm{A}>3.0$ & $\begin{array}{l}\text { It is not conducive to the removal of } \\
\text { atmospheric pollutants }\end{array}$ \\
\hline Grad Six & $\mathrm{A} \leq 3.0$ & $\begin{array}{l}\text { It is very detrimental to the removal of } \\
\text { atmospheric pollutants }\end{array}$ \\
\hline
\end{tabular}

Based on the methods provided by the above standard, this study calculated the historical atmospheric self-purification index of Beijing. The data comparison between the mean value of the past 5 years and 2020 is shown in Figure 10. 


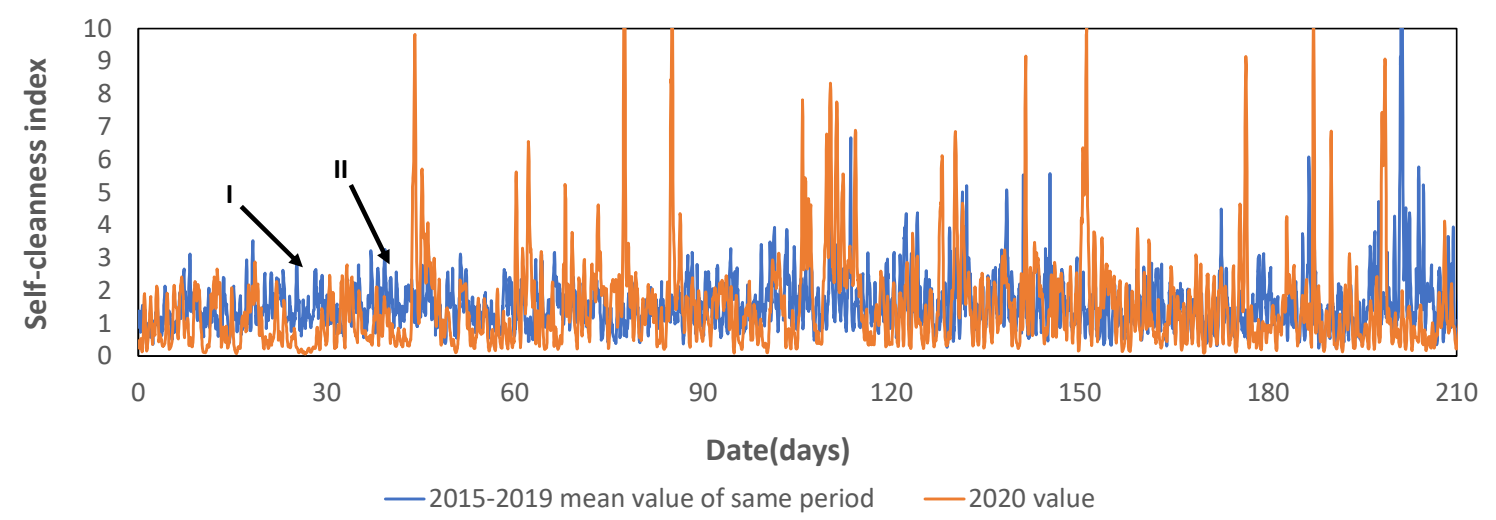

Figure 10. Beijing's atmospheric self-purification ability index, year 2020 vs. same period average across 2015 to 2019.

In the early stage of the epidemic (from late January to early mid-February), the meteorological conditions were extremely unfavourable for the pollutants to spread out compared with the same period in history, when the periods coincided with two consecutive control periods. This corresponds to the two obvious peaks (peak I and peak II) of Beijing's PM2.5 (Figure 3) at the beginning of the year compared with the same period in history. This directly led to the abnormal behaviour of Beijing's PM2.5 and $\mathrm{SO}_{2}$ pollution not falling but rising at the beginning of the epidemic.

Regarding changes with $\mathrm{NO}_{2}$, it is difficult to find continuous ground data with sufficiently high time resolution. Therefore, this study did not analyse the peripheral migration of $\mathrm{NO}_{2}$. However, as pointed out in [15], the stability of $\mathrm{NO}_{2}$ in the air is low. $\mathrm{NO}_{2}$ is highly unlikely participate the large-scale migration which lasts days. The previous comparison results show that the changes in Beijing's $\mathrm{NO}_{2}$ pollution under the influence of the epidemic are significantly different from the performance of $\mathrm{PM} 2.5$ and $\mathrm{SO}_{2}$. The significant reduction in $\mathrm{NO}_{2}$ during the epidemic indicates that the $\mathrm{NO}_{2}$ emissions sources in Beijing are mainly those easily affected by local people's activity, such as transportation traffic and the tertiary industries. Given that nitrogen oxides mainly come from the combustion process, including industrial boilers, power plants, and transportation, it can be reasonably inferred that Beijing's $\mathrm{NO}_{2}$ emissions mainly come from transportation, rather than (at least not entirely) the impact of surrounding industries.

Same algorithm is used to analyse the amount of PM2.5 migration in Wuhan, and the results are shown in Figure 11. It shows that Wuhan is significantly different from Beijing in terms of pollutant migration. The import and export of PM2.5 in Wuhan are roughly balanced, with a slightly net annual export, rather than being a typical pollutant import city like Beijing. 


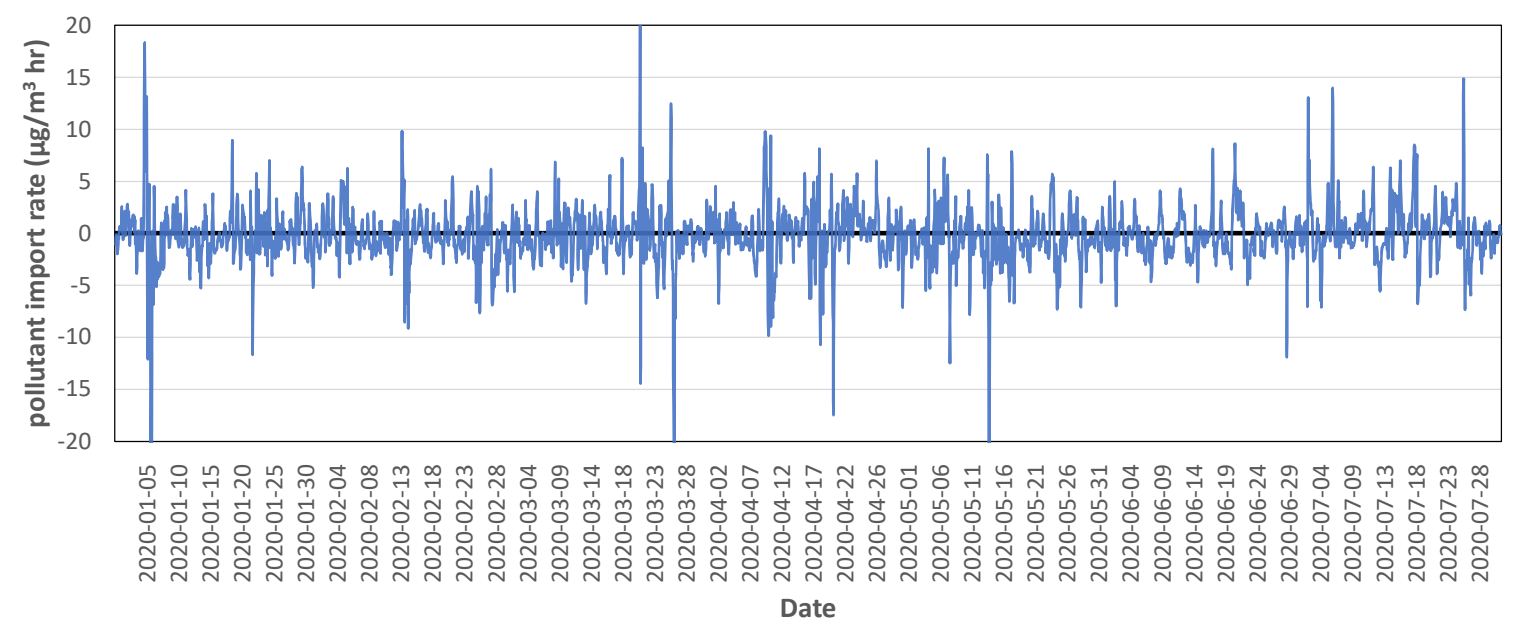

Figure 11. Analysis of PM2.5 migration rate around Wuhan during the epidemic.

Therefore, the local PM2.5 emission sources in Wuhan have a greater impact on local pollution comparing to the PM2.5 migration from neighbourhood. The main heavy industries in Wuhan include iron and steel, metallurgy, shipbuilding, and automobiles. The steel industry is not affected by the epidemic control actions due to its industry characteristics, but the shipbuilding and automobile industries are more vulnerable to the epidemic control and production declines. It can be reasonably inferred that during the epidemic period, some local industries in Wuhan reduced or stopped production, resulting in a slight decrease in PM2.5 in Wuhan, which is different from that in Beijing.

Because Wuhan was the earliest place where the epidemic was discovered and under the strictest controls during the entire epidemic, the suppression of human activities, including transportation, can be inferred to be much stronger than other cities. This is manifested in the substantial reduction of its $\mathrm{NO}_{2}$ pollution, especially in the early stage of the epidemic: During the city's first-level response period, its pollution volume dropped by an astonishing $48 \%$ (overall $40 \%$ reduction for the whole period).

Therefore, from the above analysis, explanations can be given to the two questions we asked.

For question 1, the reason why PM2.5 behaves differently in Beijing and Wuhan is that other than local emissions, global migration of pollutant affects Beijing much more than Wuhan. The meteorological condition of Beijing makes it vulnerable to pollutant imports and the emission sources in the neighbourhood of Beijing significantly take control of Beijing's pollutions. Such sources happen to be heavy industries which are much less affected by the epidemic control. While Wuhan is more of a local-emission-controlled city which is more affected by local control actions.

For question 2, the reason why PM2.5 and NOx behave differently even under same control actions is that their main sources of emission are different. PM2.5 is more of an industrial pollutant which is less affected by the epidemic control actions; while NOx is more of a municipal pollutant coming from transportation traffics and tertiary industries which is easily affected by the human activity suppression by the epidemic control policies.

\section{Conclusions}

During the epidemic, the pollution of PM2.5 in Beijing did not decrease significantly. On the contrary, there was a significant increase at the end of January and the beginning of February, while $\mathrm{NO}_{2}$ decreased significantly. Wuhan City's PM2.5 experienced a slight drop during the epidemic control period, and $\mathrm{NO}_{2}$ dropped significantly. 
1. The analysis of the migration of pollutants in the surrounding areas shows that as far as PM2.5 is concerned, Beijing is a net importing city. So, its pollution is greatly affected by the surrounding areas. During the epidemic, surrounding heavy industries were not affected as much as transportation and tertiary industries. Many nearby large heavy industries did not stop production during the epidemic. Since a lot of PM2.5 came from these large heavy industries, Beijing PM2.5 has not changed much. At the same time, the abnormally low atmospheric self-purification capacity in January and February in 2020 also attributed to the adverse effects of the meteorological conditions at that time.

2. The significant decrease in Beijing's NO2 pollution during the epidemic control period indicates that the NO2 pollution in this place is significantly affected by local non-industrial emissions.

3. Pollutant migration analysis showed that Wuhan is a slightly net exporter of PM2.5. In addition, Wuhan is a heavy industrial city with many local industrial pollution sources. Therefore, the slight decrease in PM2.5 in Wuhan during the epidemic indicates that its pollution situation was mainly driven by local industrial emissions. Affected by the epidemic controls, personnel are not allowed to go out to manufactories which led to shutdowns of some factories. Hence the epidemic controls reduced PM2.5 emissions.

4. The sharp drop in $\mathrm{NO}_{2}$ in Wuhan can be attributed to the sharp drop in traffic and tertiary industry activities during the epidemic.

In general, it can be concluded that in cities similar as Beijing and Wuhan, the source of PM2.5 are mainly industrial, while that of NOx are mainly municipal and tertiary industries. In addition, global migration of PM2.5 can be a major factor air pollution for importer cities like Beijing, which can yield more significant effects than local factors.

Through the analysis of this study, we suggest that the pollution control of Beijing, especially PM2.5, should not be limited to the local area, but should start with the surrounding areas-mainly including the Beijing-Tianjin-Hebei region-linkage. On the other hand, $\mathrm{NO}_{2}$ control should be locally focused on management of traffic vehicles within this city. As for a heavy industrial city like Wuhan, it should pay more attention to local pollution control, whether it is PM2.5 or NOx. Both industrial control and traffic control are important.

Through the foregoing discussion, by calculations using NASA satellite data, both meteorological conditions and pollutant migration are highly correlated with the degree of pollution. Therefore such calculations can effectively forecast the future air quality. This shows the effectiveness of the satellite monitoring system. Therefore, based on the existing ground monitoring, we can strengthen the satellite real-time monitoring methods. Combined with effective predictive models, according actions can be taken in advance before the arrival of heavy pollution, such as restricting the number of cars on road. This early warning mechanism will more effectively relieve pollution pressure.

In addition, this paper finds that the above model data based on satellite monitoring can effectively analyse the net migration of pollutants and locate the main pollution output locations. Using this method combined with large-scale data analysis can effectively determine the main output source of pollutants, to accurately locate and control the pollution source.

Funding: This research received no external funding

Institutional Review Board Statement: Not Applicable

Informed Consent Statement: Not Applicable

Data Availability Statement: Please refer to reference for multiple DOI's involved

Acknowledgments: During the writing of this article, Dr. Chen Dingjiang, Associate Professor of the Department of Chemical Engineering of Tsinghua University, provided guidance on research 
ideas, the logical structure of the article, and the standard of writing. Deeply appreciate their time, effort, and more importantly the professional opinion and guidance!!!

Conflicts of Interest: The author declares no conflict of interest.

\section{References}

1. World Heath Organization. Air Pollution. Available online: https://www.who.int/health-topics/air-pollution\#tab=tab_2 (accessed on 21/8).

2. $\quad$ Silva, R.A.; West, J.J.; Zhang, Y.; Anenberg, S.C.; Lamarque, J.-F.; Shindell, D.T.; Collins, W.J.; Dalsoren, S.; Faluvegi, G.; Folberth, G.; et al. Global premature mortality due to anthropogenic outdoor air pollution and the contribution of past climate change. Environmental Research Letters 2013, 8, 034005, doi:10.1088/1748-9326/8/3/034005.

3. Turpin, B.J.; Lim, H.-J. Species Contributions to PM2.5 Mass Concentrations: Revisiting Common Assumptions for Estimating Organic Mass. Aerosol Science and Technology 2001, 35, 602-610, doi:10.1080/02786820119445.

4. Global Modeling and Assimilation Office (GMAO). MERRA-2 tavg1_2d_aer_Nx: 2d,1-Hourly,Time-averaged,SingleLevel,Assimilation,Aerosol Diagnostics. 2015, 5.12.4, doi:10.5067/KLICLTZ8EM9D.

5. Nickolay A. Krotkov, L.N.L., Sergey V. Marchenko, Edward A. Celarier, Eric J.Bucsela, William H. Swartz, Joanna Joiner and the OMI core team. OMI/Aura NO2 Cloud-Screened Total and Tropospheric Column L3 Global Gridded 0.25 degree $x$ 0.25 degree. 2019, doi:10.5067/Aura/OMI/DATA3007.

6. Global Modeling and Assimilation Office (GMAO). MERRA-2 tavg1_2d_csp_Nx: 2d,1-Hourly,Time-averaged,SingleLevel,Assimilation,COSP Satellite Simulator. 2015, 5.12.4, doi:10.5067/VJAFPLI1CSIV.

7. Global Modeling and Assimilation Office (GMAO). MERRA-2 tavg1_2d_flx_Nx: 2d,1-Hourly,Time-Averaged,SingleLevel,Assimilation,Surface Flux Diagnostics. 2015, 5.12.4, doi:10.5067/7MCPBJ41Y0K6.

8. Global Modeling and Assimilation Office (GMAO). MERRA-2 tavg1_2d_slv_Nx: 2d,1-Hourly,Time-Averaged,SingleLevel,Assimilation,Single-Level Diagnostics. 2015, 5.12.4, doi: 10.5067/VJAFPLI1CSIV.

9. Jia, C. Hubei province to reduce emergency response to level 3 and adjust control actions accordingly. Available online: https://www.sohu.com/a/401522397 114988 (accessed on 21/8).

10. Phoenix News Hubei. 98 days of Wuhan from level one to level two for epidemic control response: we never stopped fighting. Available online: http://hb.ifeng.com/a/20200502/14205918_0.shtml (accessed on 21/8).

11. Sina News Hubei. Hubei province to reduce level one to level two on epidemic control. Available online: http://hb.sina.com.cn/news/j/2020-05-02/detail-iirczymi9460785.shtml (accessed on 21/8).

12. Beijing Government Policy Broadcasting. Beijing to reduce to level three emergency response to public health incidents. Available online: http://www.gov.cn/xinwen/2020-07/19/content 5528218.htm (accessed on 30/12).

13. Beijing Municipal Health Commission. Health guidlines for Beijing reducing level one to level two for epidemic control Available online: http://wjw.beijing.gov.cn/xwzx_20031/wnxw/202004/t20200429_1888332.html (accessed on 30/12).

14. Sohu News. Emergency alert! Beijing to launch level one response and actions will be implemented! Available online: https://www.sohu.com/a/368995697_197969 (accessed on 21/8).

15. Li, J. Data Analysis and Muti-period Model Building of Air Quality in Beijing. Tsinghua University, Beijing, 2018.

16. Hebei Provincial Environmental Protection Bureau. Preparation instructions of standard of ultra-low air pollutant emission for steel industry (draft for comments) 2018.

17. Hebei Provincial Bureau of Statistics. Productivity of major large scale industrial products. Available online: http://tij.hebei.gov.cn/cms/www/index_search.do?1=1\&channel=527\&template=101377847388054\&search_select=field_cont ent\&search key=\%E8\%A7\%84\%E6\%A8\%A1\%E4\%BB\%A5\%E4\%B8\%8A\%E5\%B7\%A5\%E4\%B8\%9A\%E4\%B8\%BB\%E8\%A6 \%81\%E4\%BA\%A7\%E5\%93\%81\%E4\%BA\%A7\%E9\%87\%8F\&pageIndex=1 (accessed on 25/8).

18. China national weather Meteorological Center; Climate Center; Environmental Impact Assessment Center. Grads of atmospheric self-purification capability. 2017, GB/T 34299-2017 